\title{
Medium Chain Triglycerides in Paediatric Practice
}

\author{
MICHAEL GRACEY, VALERIE BURKE, and CHARLOTTE M. ANDERSON \\ From the Institute of Child Health, Nuffield Building, Francis Road, Birmingham 16
}

Gracey, M., Burke, V., and Anderson, C. M. (1970). Archives of Disease in Childhood, 45, 445. Medium chain triglycerides in paediatric practice. Medium chain triglycerides (MCT) bypass the steps necessary for the absorption of long chain fats (LCT), and so have theoretical grounds for their use in various disease states, particularly malabsorptive disorders. In childhood, MCT have particular advantages since they allow restriction of dietary long chain fats without limiting the intake of protein necessary for growth while providing adequate calories.

In malabsorptive states, MCT have been used mostly in cystic fibrosis, where they may reduce steatorrhoea. However, the long-term growth patterns of these children are dependent on the extent and severity of their chest disease. MCT may be a useful source of calories for those with anorexia due to infection or liver disease and in babies recovering from meconium ileus. The decrease in offensive stools, flatus, and abdominal discomfort improves well-being and social acceptability which is important for many schoolchildren and adolescents. Rectal prolapse may be helped.

Where there is loss of the small intestinal absorptive surface, particularly after massive small bowel resection, MCT can help to maintain weight and nutrition. They may also be a useful supplementary nutritional measure in patients severely affected with coeliac disease while awaiting response to a gluten-free diet, and in patients with regional enteritis.

In children with liver disease, MCT provide a ready source of calories while avoiding the loss of fat in their stools. Infants with neonatal hepatitis or biliary atresia remain well nourished, and some older children with liver disease grow more rapidly and have fewer and less offensive stools and less abdominal discomfort.

Where an abnormal number of faecal organisms colonize the small intestine ('contaminated small bowel syndrome' or 'blind loop syndrome') intraluminal bile salts become deconjugated and cause steatorrhoea. A combination of antibiotic and surgical treatment is usually indicated, but MCT can be used to improve nutrition before operation and may be indicated for associated conditions, such as massive intestinal resection.

MCT have also been helpful in patients with defective chylomicron formation due to a- $\beta$-lipoproteinaemia.

In the congenital and less commonly encountered acquired lymphatic disorders in childhood, MCT have given encouraging results. This group includes patients with gross protein and fat loss due to intestinal lymphangiectasia and others with lymphatic anomalies at other sites.

Hyperchylomicronaemia (familial fat-induced hypertriglyceridaemia) responds well to dietary treatment with MCT.

A decade has passed since it was shown that medium chain triglycerides (MCT) could be fed to replace the entire dietary fat with maintenance of body weight (Hashim, Arteaga, and Van Itallie, 1960). Since then their characteristics of absorption have been clearly elucidated (Hofmann, 1968; Isselbacher, 1968), and their metabolism is the subject of extensive investigation (Scheig, 1968a; Holt, 1968). There have been many articles relating to the biochemical and metabolic effects of MCT, and since they have become available in commercial preparations there have been numerous clinical studies, principally in adults, in whom the place of MCT therapy has been defined (Holt, 1967; 
Senior, 1969). We do not intend to review this material in detail but to clarify the indications for the use of MCT in paediatric practice.

\section{Metabolism of MCT}

Unlike long chain fats (LCT), significant absorption of MCT occurs in the absence of bile acids and pancreatic lipase. Isselbacher (1966) has shown that uptake and absorption of MCT are more rapid than LCT, even when practically no intraluminal lipase is present. MCT are transported across the small intestinal epithelial cell rapidly, possibly because of the presence of an intracellular lipase (Playoust and Isselbacher, 1964). The later stages of absorption of MCT also differ from LCT, as most of the MCT passes directly into the portal venous system without forming chylomicrons (Bloom, Chaikoff, and Reinhardt, 1951).

In the liver MCT are rapidly oxidized to 2-carbon fragments which are available for various metabolic pathways (Scheig, 1968a). Because of these differences in transport and metabolism, MCT induce changes in serum lipids. However, the change in lipid pattern is not identical in all patients (Furman et al., 1965; Kuo and Huang, 1965), and must be interpreted in the knowledge of the pattern before the introduction of MCT into the diet (Tamir et al., 1969).

\section{Possible Advantages of MCT Feeding}

In bypassing the steps necessary for absorption of long chain fats, MCT provide a source of calories while reducing the amount of malabsorbed fat remaining in the stools. Steatorrhoea not only correlates with negative nitrogen balance (Pinter, Hyman, and Bolanos, 1969) but in itself results in unpleasant symptoms such as abdominal distension and discomfort, and offensive, often frequent, stools. In lymphatic disorders, such as intestinal lymphangiectasia, a dietary load of long chain fats actually increases enteric protein loss, and where chylous effusions unamenable to operation are the main clinical problem, these can only be reduced in volume by decreasing the content of LCT in the diet.

In the past low-fat diet has been used to manage these conditions (Jeffries, Chapman, and Sleisenger, 1964), and in adults, who accept an MCT diet less readily than children, low fat diets are widely used, though they are unattractive and though patients often do not maintain the required caloric intake. Low fat diets have particular disadvantages in children. Most foods which are low in fat also have a low protein content, and it is difficult to provide adequate protein intake for growth requirements in children. Essential fatty acid (EFA) deficiency may also result, and in one child with chylous ascites, clinical features of EFA deficiency, including dry, scaly skin with eczematous lesions, coarse, thick, and sparse hair, and repeated respiratory infections, appeared after 6 months of a diet containing $10 \mathrm{~g}$. fat daily (Warwick et al., 1959). Supplements of linoleic acid are not well tolerated and may cause diarrhoea (Tamir et al., 1969). Though pure MCT oil does not contain linoleic acid, there has been no clinical evidence of EFA deficiency in children treated for up to 3 years on an MCT diet unsupplemented by linoleic acid (Tamir et al., 1969). However, the commercially available milk formula containing MCT also contains EFA supplements and is, in our experience, the most satisfactory basis for MCT diets in children. This milk product is usually well accepted by children.

\section{Sources of MCT (see Table I)}

Estimates of the MCT content of naturally occurring fats are probably too low because of

TABLE I

Commercially Available MCT Products

\begin{tabular}{|c|c|c|c|c|}
\hline MCT Oil & \multicolumn{3}{|c|}{ Supplier } & $\begin{array}{l}\text { Available on } \\
\text { Prescription } \\
\text { form E.C.10 } \\
\text { (N.H.S.) }\end{array}$ \\
\hline Trufood MCT Oil & \multicolumn{3}{|c|}{$\begin{array}{l}\text { Trufood Ltd., Guild- } \\
\text { ford, Surrey }\end{array}$} & Yes \\
\hline $\begin{array}{l}\text { Mead Johnson } \\
\text { MCT (7010X) } \\
\text { oil }\end{array}$ & \multicolumn{3}{|c|}{$\begin{array}{l}\text { Mead Johnson Research } \\
\text { Center, Evansville, } \\
\text { Indiana 47721, U.S.A. }\end{array}$} & No \\
\hline Alembicol D & \multicolumn{3}{|c|}{$\begin{array}{l}\text { E. J. R. Lovelock, } \\
\text { Oaklands House, } \\
\text { Oaklands Drive, } \\
\text { Sale, Manchester }\end{array}$} & Yes \\
\hline S.H.S. MCT Oil & \multicolumn{3}{|c|}{$\begin{array}{l}\text { Scientific Hospital } \\
\text { Supplies, 23 Queens- } \\
\text { land Street, Liverpool } \\
7\end{array}$} & No \\
\hline \multirow[t]{2}{*}{ MCT Milk } & \multicolumn{3}{|c|}{$\begin{array}{c}\text { Composition of Powder } \\
(\%)\end{array}$} & \\
\hline & Protein & Fat & $\begin{array}{l}\text { Carbohyd- } \\
\text { rate }\end{array}$ & \\
\hline $\begin{array}{l}\text { Trufood } \\
\text { MCT Milk (1) }\end{array}$ & $26 \cdot 6$ & $28 \cdot 0$ & $40 \cdot 6^{\star}$ & Yes \\
\hline $\begin{array}{l}\text { Mead Johnsont } \\
\text { Portagen } \\
\text { (Triglyde) }\end{array}$ & $18 \cdot 6$ & $22 \cdot 5$ & $52 \cdot 7 \ddagger$ & Yes \\
\hline
\end{tabular}

^Dextrimaltose.

†Available in U.K. from Bristol Laboratories Ltd., Astronaut House, Hounslow Road, Feltham, Middlesex.

$\ddagger$ Lactose, sucrose, and starch. 
inaccuracies in their detection by earlier methods (Scheig, 1969). However, coconut oil contains at least $10 \%$ of its fat as MCT, and butter contains more than $8 \%$. Coconut oil is used as the raw material for the manufacture of commercially available MCT oils. This oil is used to replace butter fat in powdered preparations which can be reconstituted to the desired 20 or 30 calories/oz. (70-110 cal./100 ml.) formula. Recently an MCT margarine preparation ${ }^{\star}$ has become commercially available in several European countries but not in the United Kingdom. However, it has been used experimentally here in several hospitals.

\section{Dietary Management}

Details of dietary management depend on the type of MCT product available. MCT oil can be given as supplements, mixed with fruit juice or other flavouring, to a patient whose diet is otherwise moderately low in fat. Care must be used in prescribing MCT oil, as its high osmolarity may cause abdominal pain, vomiting, and diarrhoea. It should be given in diluted form, introduced into the diet slowly, and ingested slowly. MCT oil can be used in cooking, but precautions are necessary because it burns easily when used for frying. However, it can be used in place of vegetable oil in most recipes.

We have had easy access to supplies of the milk formula product which has been readily available in Australia and North America. This product is simple to use as the basis for MCT diets in children. In infants the formula reconstituted to $20 \mathrm{cal} . / \mathrm{oz}$. (70 cal./100 ml.) has been used in place of the usual milk formula, and solid foods have been introduced in the usual way, mixed if necessary with MCT milk.

In older children we aim to give about half the dietary fat as LCT so that the diet is not severely restricted. The MCT milk product is used to provide the rest of the calories allocated to fat. In this way protein intake is unrestricted. Most children have found this diet acceptable, and in the few who have complained of the taste of the MCT milk, this is easily masked when substituted for cow's milk in the preparation of foods such as custard and ice-cream. Sample menus have been detailed elsewhere by other authors (Schizas et al., 1967; Francis and Dixon, 1970).

\section{Malabsorptive Disorders}

(a) Pancreatic disease. Cystic fibrosis (CF) is the most commonly encountered cause of pan-

^Margarine-Union GMBH, Hamburg.

tPortagen (Mead Johnson): Triglyde (Mead Johnson). creatic insufficiency in childhood. The place of pancreatic extracts in promoting fat absorption in patients with pancreatic disease is controversial (Dyer and Dawson, 1968; Norman and Gibbons, 1968). Using 3-4 g. pancreatic extract with each meal in older children and proportionately smaller doses in infants, this effect is often minor, and large and unpalatable amounts may be needed to avoid steatorrhoea completely. In fact, steatorrhoea is rarely eliminated (Burke and Anderson, 1967), perhaps because the absorptive defect in CF may not be entirely explained by deficient exocrine pancreatic secretions. A layer of coarse fibrillar material and amorphous debris covers the epithelial cells of the small intestinal mucosa (Freye et al., 1964), and may provide a further barrier preventing the complete absorption of fat and other nutrients in such patients.

MCT diets will further decrease steatorrhoea in children with pancreatic insufficiency due to $C F$ (Kuo and Huang, 1965; Burke and Anderson, 1967; Kühni, 1968), and the early results of clinical studies suggested that this form of therapy might be helpful in improving the growth of these children. However, a more recent study (Gracey, Burke, and Anderson, 1969a) has indicated that there is no particular advantage in weight gain in a group of infants with adequately treated chest disease receiving MCT over a period of 3 years. In spite of this, there are several effects of this form of feeding which may be advantageous in patients with CF.

Improved caloric intake. MCT is a convenient and readily absorbed source of calories, providing $8.4 \mathrm{Kcal} . / \mathrm{g}$. in comparison with $4 \mathrm{Kcal} . / \mathrm{g}$. from carbohydrate. Usually children with CF who feel well will eat enough to provide a caloric intake adequate for growth, but this may not be so in those whose appetites are poor because of infection or liver disease. Weight loss is common during a severe exacerbation of chest infection, and these children are often slow to regain their usual weight. In such patients and in infants recovering from operation for meconium ileus, MCT may be useful in accelerating restoration of the usual weight, though, in our experience, further weight gain does not continue at this rate (Burke and Anderson, 1967).

Characteristics of stools. MCT feeding improves the nature and number of stools and the amount of flatus passed. In some patients these unpleasant symptoms may cause considerable discomfort and embarrassment particularly in schoolchildren and adolescents; mothers of babies with CF often 
complain of the overwhelming offensiveness of the babies' nappies. In such patients MCT may be helpful.

Abdominal discomfort and rectal prolapse. Troublesome abdominal discomfort, distension, and pain related to gaseous distension and inspissation of intestinal contents occur not uncommonly in CF (Gracey, Burke, and Anderson, 1969b). Severe abdominal pain or even intestinal obstruction occurs (Mullins, Talamo, and di Sant'Agnese, 1965), and may be aggravated by abnormal bulk of intestinal contents. These symptoms are improved by using MCT (Gracey and Anderson, 1969). Similarly, troublesome rectal prolapse may be helped by reducing stool bulk (Burke and Anderson, 1967).

Other disorders of exocrine pancreatic function are rare in childhood, and apart from CF we have had experience only with the syndrome of pancreatic insufficiency and neutropenia (Burke et al., 1967). In this condition, steatorrhoea is more severe in infancy and may spontaneously improve with age, in spite of persisting lack of pancreatic enzymes. This is in contrast to patients with CF where steatorrhoea persists after the addition of pancreatic extracts and does not improve with age. Though MCT will decrease steatorrhoea in this unusual condition, their use is rarely necessary because of the clinical course and the satisfactory response to pancreatic enzyme replacement.

(b) Liver disease. The steatorrhoea which accompanies liver disease in adults has been associated with a number of possible aetiological mechanisms (Losowsky and Walker, 1969). These include abnormal pancreatic function (Sun, Albacete, and Chen, 1967), inadequate and abnormal bile salt production by the liver (Krone et al., 1968; Blum and Spritz, 1966), the presence of abnormal small intestinal bacterial flora (Martini et al., 1957), and the presence of oedema and malfunction of the small intestinal mucosa in patients with portal hypertension (Astaldi and Strosselli, 1960).

In childhood the underlying clinical disorders associated with liver disease are not as varied as in adult life, and there have been fewer studies of children with malabsorption and liver disease. However, in a study of infants with neonatal hepatitis or biliary atresia and in older children with Wilson's disease or 'juvenile active hepatitis' no abnormality of pancreatic function, small intestinal mucosa, or small intestinal flora was found (Burke and Danks, 1966a). Mucosal abnormalities resembling the changes in coeliac disease have been found in 2 children with portal hypertension, both of whom had steatorrhoea (Anderson, 1966). Bile salts were conjugated but present in reduced amounts in babies with neonatal hepatitis, who also showed defective metabolism of C14-labelled cholic acid (Norman, Strandvik, and Zetterström, 1969). Though limited, the available evidence points towards defective metabolism of bile salts as the reason for malabsorption in many children with liver disease.

The use of pancreatic extracts and bicarbonate supplements failed to improve steatorrhoea in children with liver disease (Burke and Danks, 1966a). The unpalatability of a low fat diet is a particular disadvantage in children who often have anorexia, and in infants skimmed milk with added sugar must provide the basis for the diet. Orally administered bile salt supplements are unsatisfactory because of the high cost of obtaining a pure preparation and because of their laxative effect.

MCT, then, offer possible advantages in the management of children with liver disease. Anorexia may lead to inadequate caloric intake, and an MCT formula will provide a readily accepted source of calories as well as avoiding the loss of fat in the stools. The use of such a formula in infants with liver disease allows optimal nutrition in those requiring laparotomy and in those with neonatal hepatitis, many of whom eventually recover. Our experience of older children with liver disease is more limited but improved growth and well-being has followed the use of an MCT diet in some of these patients (Burke and Danks, 1966a; Scheig, 1968b).

There are theoretical objections to the use of MCT in patients with liver disease, for in patients with portal-systemic shunts MCT may bypass the liver and reach sufficient levels (Lindscheer et al., 1966) in the systemic circulation to produce central nervous system depression (Samson, Dahl, and Dahl, 1956). We have not observed this effect clinically in our patients managed with MCT, even though they included two teenage boys with $\mathrm{CF}$, chronic liver disease, and large portal-systemic shunts.

We believe that MCT have an important place in the management of children with liver disease. Infants with neonatal hepatitis or biliary atresia will remain well nourished, and older children with liver disease grow more rapidly and have fewer and less offensive stools and less abdominal discomfort.

(c) Malabsorption associated with abnormal small intestinal flora ('contaminated small bowel syndrome'). In the presence of abnormal small bowel flora, which occurs in patients with intestinal stasis, conjugated bile salts entering the duodenum become unconjugated and cannot effectively con- 
tribute to micelle formation, an essential step in the absorption of LCT, and steatorrhoea results. This situation is usually best treated with appropriate antibiotics and surgical correction of the intestinal abnormality where this is possible. MCT therapy is not indicated in these patients unless it is necessary to improve their nutrition before operation or if there is an associated abnormality (e.g. massive small bowel resection) which in itself requires treatment with an MCT diet.

(d) Loss of intestinal absorptive surface. Extensive resection of the small intestine in infants and children may lead to malnutrition with poor growth and deficiency states. Steatorrhoea results from loss of the normal area for fat absorption, or less commonly because of interruption of the enterohepatic circulation of bile salts when the distal ileum, the site for normal absorption of bile salts, has been resected (Austad, Lack, and Tyor, 1967). In some patients intestinal stasis leads to abnormal small intestinal flora and contributes to steatorrhoea (Tabaqchali and Booth, 1967), and these should be dealt with along the lines previously mentioned.

MCT have been shown to reduce steatorrhoea and improve weight gain in infants and children with both proximal and distal small intestinal resections (Burke and Anderson, 1967). Caution must be exercised in introducing MCT preparations into the diet in the early post-operative period, as the sugar content of the formulae may produce severe diarrhoea in these patients who often have a temporary form of sugar intolerance (Burke and Anderson, 1966a).

In untreated coeliac disease the small intestinal surface area is greatly diminished (Pinter et al., 1964), and the epithelial absorptive and digestive enzyme systems extensively damaged (Townley and Anderson, 1967; Lindberg, Nordén, and Josefsson, 1968), and while a gluten-free diet is specific therapy for this disorder, one occasionally encounters very ill or undernourished patients in whom weight gain is of prime importance and is rapidly achieved with MCT while awaiting the response to exclusion of gluten. Again one must carefully consider the sugar content of the preparation when using MCT in this situation, as intolerance to lactose sometimes occurs.

MCT are beneficial in various other diseases affecting the small intestinal mucosa. In regional enteritis (Greenberger, Ruppert, and Tzagournis, 1967) encouraging results have been reported. The prime lesion in tropical sprue appears to be intestinal mucosal damage (Mathan, Joseph, and
Baker, 1969). The therapy of this disorder is still debatable, but Cancio and Menéndez-Corrada (1964) have used MCT, and there are good theoretical grounds for such an approach to therapy. Response to antibiotics and folic acid is unpredictable, the patients are often emaciated and the administration of MCT would be a logical adjunct to therapy to aid weight gain and remission. Unfortunately, this material is not readily available in the underdeveloped countries where tropical sprue is common.

(e) A- $\beta$-lipoproteinaemia. In this disease chylomicron formation is defective and on a normal fat diet triglyceride accumulates in the mucosal cells and does not pass further into the lymphatics. The condition is rare and few patients have been treated with MCT. In one 12-year-old patient (Isselbacher et al., 1964) who had failed to gain weight in the preceding year, weight increased by $3 \mathrm{~kg}$. in the 5 months after starting an MCT diet, and steatorrhoea decreased. Others have confirmed the decrease in steatorrhoea (Burke and Anderson, 1967; Leyland et al., 1969), but there are not yet sufficient data available to indicate the value of MCT in this condition. MCT certainly provide a form of fat which can be absorbed in these patients, and a trial of their use seems indicated.

(f) Other disorders of absorption. In some patients, particularly young infants, the cause of steatorrhoea may be undiagnosed even after extensive investigation, and in others their debility makes investigation hazardous. Maintenance of nutrition becomes a problem in such patients and, as MCT bypass a number of steps necessary for absorption of LCT, an MCT diet may be successful in establishing weight gain (Burke and Anderson, 1967).

MCT are also useful in the management of infants with temporary monosaccharide malabsorption (Burke and Danks, 1966b) whose carbohydrate intake must be restricted to control loss of fluid in the stools. In these infants it is difficult to achieve sufficient calorie intake to maintain nutrition and the loss of fat in the stools must be minimized. The MCT milk preparation cannot be used because of its sugar content, but a formula based on MCT oil mixed with protein, vitamins, and minerals is satisfactory in improving the nature of the stools and preventing weight loss (Harries and Francis, 1968).

Rarely MCT also have a place in managing infants with secondary disaccharidase deficiency. Mucosal abnormalities similar to coeliac disease occur, and there may be malabsorption of fat as well as disaccharides (Burke, Kerry, and Anderson, 
TABLE II

Indications for MCT in Paediatric Practice

\begin{tabular}{|c|c|c|}
\hline Abnormality & Clinical Disorder & $\begin{array}{l}\text { MCT } \\
\text { Therapy } \\
\text { Useful }\end{array}$ \\
\hline $\begin{array}{l}\text { Impaired fat absorption } \\
\text { (a) Intraluminal defect } \\
\text { (1) Deficiency of } \\
\text { pancreatic lipase }\end{array}$ & $\begin{array}{l}\text { Cystic fibrosis } \\
\text { Pancreatic insufficiency } \\
\text { and neutropenia }\end{array}$ & $\begin{array}{l}\text { Yes } \\
\text { Rarely }\end{array}$ \\
\hline (2) Liver disease & $\begin{array}{l}\text { Neonatal hepatitis } \\
\text { Biliary atresia } \\
\text { Juvenile active } \\
\text { hepatitis } \\
\text { Wilson's disease } \\
\text { With cystic fibrosis }\end{array}$ & $\begin{array}{l}\text { Yes } \\
" \\
" \\
" \\
"\end{array}$ \\
\hline $\begin{array}{l}\text { (3) Deficiency of } \\
\text { normal bile salts }\end{array}$ & $\begin{array}{l}\text { 'Contaminated small- } \\
\text { bowel syndrome' }\end{array}$ & Rarely \\
\hline (b) Mucosal defect & $\begin{array}{l}\text { Coeliac disease } \\
\text { Massive small bowel } \\
\text { resection } \\
\text { Regional enteritis }\end{array}$ & $\begin{array}{l}\text { Rarely } \\
\text { Yes } \\
\text { Yes }\end{array}$ \\
\hline $\begin{array}{l}\text { (c) Defective } \\
\text { chylomicron } \\
\text { formation }\end{array}$ & A- $\beta$-lipoproteinaemia & Possibly \\
\hline Lymphatic abnormality & $\begin{array}{l}\text { Intestinal lymphangiec- } \\
\text { tasia } \\
\text { Chylothorax } \\
\text { Chyloperitoneum }\end{array}$ & $\begin{array}{l}\text { Yes } \\
\text { Yes } \\
\text { Yes }\end{array}$ \\
\hline Hyperlipidaemia & Hyperchylomicronaemia & Yes \\
\hline
\end{tabular}

1965) contributing to the emaciation seen in some infants in whom the disorder has been unrecognized for some months. Though the appropriate disaccharide-free feeding is the first step in the management, severely debilitated infants will benefit from the short-term use of MCT.

\section{Lymphatic abnormalities}

In childhood, impaired drainage of lymph from the small intestine usually results from intestinal lymphangiectasia, and is a rare cause of malabsorption and intestinal protein loss. Other causes of interruption of intestinal lymphatic drainage in childhood, such as trauma (Tamir et al., 1968b), tuberculosis (Gracey and Gooch, 1968), malrotation (Burke and Anderson, 1966b), or malignancy are extremely rare. In the congenital type of disorder lymphatics other than those of the intestine may be affected resulting in chylothorax, chylous ascites, or peripheral oedema (Poley et al., 1967).

MCT are useful in decreasing steatorrhoea in patients with abnormalities of the intestinal lymphatics by improving growth and the stool pattern, and lessening intestinal protein loss (Table II). An MCT diet is more acceptable to most children than a low fat diet which is the only alternative method of managing such patients, unless resection of the affected segment of bowel is possible in intestinal lymphangiectasia or if the lymphatic obstruction can be relieved (Burke and Anderson, 1966b).

MCT are also valuable in managing the other manifestations of lymphatic abnormalities, chylothorax, chyloperitoneum, and peripheral oedema, which may be associated with intestinal lymphangiectasia. The reduction in volume of lymph following substitution of MCT for LCT results in decreased volume of extravasated fluid; chylous, pleural, and peritoneal effusions require less frequent aspiration, and peripheral oedema decreases. This reduces the loss of protein and lymphocytes in the effusions, and decreases the frequency of infections in these children (Poley et al., 1967).

We recommend an MCT diet as the treatment of choice in children with lymphatic abnormalities. Usually these are congenital, but it has also proved useful in the one patient reported with chylous ascites associated with tuberculosis (Gracey and Gooch, 1968), in reducing the volume of ascitic fluid while awaiting response to antituberculous therapy.

\section{Disorders of Lipid Metabolism}

MCT lead to a fall in the amount of free long chain fatty acids in serum, possibly by direct action on adipose tissue (Tamir et al., 1968a), though other explanations have been suggested (Holt, 1968).

MCT cause a dramatic fall in serum triglyceride levels in patients with hyperchylomicronaemia (familial fat-induced hypertriglyceridaemia). This condition is usually caused by a lack of lipid 'clearing factor', lipoprotein lipase (Fredrickson and Lees, 1966), and patients have excessive accumulation of chylomicrons in serum because of an inability to clear dietary fat. A virtually fat-free diet will rapidly clear the serum chylomicrons and lower the serum triglyceride level (Lloyd, 1968); however, such a diet is unpalatable, especially to children, and MCT provide a convenient and logical way to approach this therapeutic problem, as they are directly absorbed into the blood-stream and thus do not result in chylomicron accumulation (Furman et al., 1965). The clinical response to dietary treatment is excellent (Lloyd, 1968).

The place of MCT in the management of other inherited disorders of lipid metabolism is not so clear cut. Long-term studies of their role in hypercholesterolaemia have not been reported, but as moderate fat restriction has an important place in the management of the disorder, MCT may provide a useful alternative diet. 
REFERENCES

Anderson, C. M. (1966). Intestinal malabsorption in childhood. Archives of Disease in Childhood, 41, 571.

Astaldi, G., and Strosselli, E. (1960). Peroral biopsy of the intestinal mucosa in hepatic cirrhosis. American fournal of Digestive Diseases, 5, 603.

Austad, W. I., Lack, L., and Tyor, M. P. (1967). Importance of bile acids and of intact distal small intestine for fat absorption. Gastroenterology, 52, 638.

Bloom, B., Chaikoff, I. L., and Reinhardt, W. O. (1951). Intestinal lymph as pathway for transport of absorbed fatty acids of different chain lengths. American fournal of Physiology, 166, 451.

Blum, M., and Spritz, N. (1966). The metabolism of intravenously injected isotopic cholic acid in Laennec's cirrhosis. Fournal of Clinical Investigation, 45, 187.

Burke, V., and Anderson, C. M. (1966a). Sugar intolerance as a cause of protracted diarrhoea following surgery of the gastrointestinal tract in neonates. Australian Paediatric fournal, 2, 219.

, and _ (1966b). Chronic volvulus as a cause of hypoproteinaemia, oedema and tetany. Australian Paediatric fournal, 2, 114.

, and - (1967). Experience with medium chain triglycerides in malabsorptive states in childhood. Australian Paediatric fournal, 3, 135.

—, Colebatch, J. H., Anderson, C. M., and Simons, M. J. (1967). Association of pancreatic insufficiency and chronic neutropenia in childhood. Archives of Disease in Childhood, 42, 147.

, and Danks, D. M. (1966a). Medium-chain triglyceride diet: its use in treatment of liver disease. British Medical fournal, 2, 1050.

- , and - (1966b). Monosaccharide malabsorption in young infants. Lancet, 1, 1117.

- Kerry, K. R., and Anderson, C. M. (1965). The relationship of dietary lactose to refractory diarrhoea in infancy. Australian Paediatric fournal, 1, 147.

Cancio, M., and Menéndez-Corrada, R. (1964). Absorption of medium chain triglycerides in tropical sprue. Proceedings of the Society for Experimental Biology and Medicine, 117, 182.

Dyer, N. H., and Dawson, A. M. (1968). Malabsorption. British Medical fournal, 2, 225.

Francis, D. E. M., and Dixon, D. J. W. (1970). Diets for Sick Children, p. 129, 2nd ed., Blackwell, Oxford.

Fredrickson, D. S., and Lees, R. S. (1966). Familial hyperlipoproteinemia. In The Metabolic Basis of Inherited Disease, 2nd ed., p. 429. Ed. by J. B. Stanbury, J. B. Wyngaarden and D. S. Fredrickson. McGraw-Hill, New York.

Freye, H. B., Kurtz, S. M., Spock, A., and Capp, M. P. (1964). Light and electron microscopic examination of the small bowel of children with cystic fibrosis. Fournal of Pediatrics, 64575.

Furman, R. H., Howard, R. P., Brusco, O. J., and Alaupovic, P. (1965). Effects of medium chain length triglyceride (MCT) on serum lipids and lipoproteins in familial hyperchylomicronemia (dietary fat-induced lipemia) and dietary carbohydrateaccentuated lipemia. Fournal of Laboratory and Clinical Medicine, 66, 912 .

Gracey, M., and Anderson, C. M. (1969). Cystic fibrosis of the pancreas in adolescence and adulthood. Australasian Annals of Medicine, 18, 91 .

—, Burke, V., and Anderson, C. M. (1969a). Assessment of medium-chain triglyceride feeding in infants with cystic fibrosis. Archives of Disease in Childhood, 44, 401.

- , and $-(1969 \mathrm{~b})$. Treatment of abdominal pain in cystic fibrosis by oral administration of $\mathrm{n}$-acetyl cysteine. Archives of Disease in Childhood, 44, 404.

- and Gooch, P. M. (1968). The use of a medium chain triglyceride diet in chyloperitoneum. Australian Paediatric fournal, 4,66 .

Greenberger, N. J., Ruppert, R. D., and Tzagournis, M. (1967). Use of medium chain triglycerides in malabsorption. Annals of Internal Medicine, 66, 727.

Harries, J. T., and Francis, D. E. M. (1968). Temporary monosaccharide intolerance. Acta Paediatrica Scandinavica, 57, 505.

Hashim, S. A., Arteaga, A., and Van Itallie, T. B. (1960). Effect of a saturated medium-chain triglyceride on serum-lipids in man. Lancet, 1, 1105.
Hofmann, A. F. (1968). Intraluminal factors in the absorption of glycerides. In Medium Chain Triglycerides. p. 9. Ed. by J. R. Senior. University of Pennsylvania Press, Philadelphia.

Holt, P. R. (1967). Medium chain triglycerides. A useful adjunct in nutritional therapy. Gastroenterology, 53, 961

(1968). Medium chain triglycerides: their absorption, metabolism and clinical applications. In Progress in Gastroenterology, vol. 1, p. 277. Ed. by G. B. J. Glass. Grune and Stratton, New York and London.

Isselbacher, K. J. (1966). Biochemical aspects of fat absorption. Gastroenterology, 50, 78.

- (1968). Mechanisms of absorption of long and medium chain triglycerides. In Medium Chain Triglycerides, p. 21. Ed. by J. R. Senior. University of Pennsylvania Press, Philadelphia. , Scheig, R., Plotkin, G. R., and Caulfield, J. B. (1964). Congenital $\beta$-lipoprotein deficiency: an hereditary disorder involving a defect in the absorption and transport of lipids. Medicine, 43, 347.

Jeffries, G. H., Chapman, A., and Sleisenger, M. H. (1964). Low-fat diet in intestinal lymphangiectasia. Its effect on albumin metabolism. New England fournal of Medicine, 270, 761.

Krone, C. L., Theodor, E., Sleisenger, M. H., and Jeffries, G. H (1968). Studies on the pathogenesis of malabsorption. Lipid hydrolysis and micelle formation in the intestinal lumen. Medicine, 47, 89.

Kühni, M. (1968). Ernährung von Kindern mit Steatorrhöe durch Fette mit mittellangkettigen Fettsäuren. Schweizerische medizinische Wochenschrift, 98, 755 .

Kuo, P. T., and Huang, N. N. (1965). The effect of medium chain triglyceride upon fat absorption and plasma lipid and depot fat of children with cystic fibrosis of the pancreas. Fournal of Clinical Investigation, 44, 1924.

Leyland, F. C., Fosbrooke, A. S., Lloyd, J. K., Segall, M. M., Tamir, I., Tomkins, R., and Wolff, O. H. (1969). Use of mediumchain triglyceride diets in children with malabsorption. Archives of Disease in Childhood, 44, 170.

Lindberg, T., Nordén, A., and Josefsson, L. (1968). Intestinal dipeptidases. Dipeptidase activities in small intestinal biopsy specimens from a clinical material. Scandinavian fournal of Gastroenterology, 3, 177.

Lindscheer, W. G., Patterson, J. F., Moore, E. W., Clermont, R. J., Robins, S. J., and Chalmers, T. C. (1966). Medium and long chain fat absorption in patients with cirrhosis. fournal of Clinical Investigation, 45, 1317.

Lloyd, J. K. (1968). Disorders of the serum lipoproteins. I. Lipoprotein deficiency states. II. Hyperlipoproteinaemic states. Archives of Disease in Childhood. 43, 393, 505.

Losowsky, M. S., and Walker, B. E. (1969). Liver disease and malabsorption. Gastroenterology, 56, 589.

Martini, G. A., Phear, E. A., Reubner, B., and Sherlock, S. (1957). The bacterial content of the small intestine in normal and cirrhotic subjects : relation to methionine toxicity. Clinical Science, 16, 35.

Mathan, V. I., Joseph, S., and Baker, S. J. (1969). Tropical sprue in children. A syndrome of idiopathic malabsorption. Gastroenterology, 56, 556 .

Mullins, F., Talamo, R., and di Sant'Agnese, P. A. (1965). Late intestinal complications of cystic fibrosis. Fournal of the American Medical Association, 192, 741.

Norman, A. P., and Gibbons, I. S. E. (1968). Pancreatic extracts in cystic fibrosis. British Medical fournal, 2, 621.

Norman, A., Strandvik, B., and Zetterström, R. (1969). Bile acid excretion and malabsorption in intrahepatic cholestasis of infancy ("neonatal hepatitis'). Acta Paediatrica Scandinavica, $58,59$.

Pinter, K. G., Hyman, H., III, and Bolanos, O. (1969). Fat and nitrogen balance with medium-chain triglycerides after massive intestinal resection. American fournal of Clinical Nutrition, 22, 14.

—, McCracken, B. H., Lamar, C., Jr., and Goldsmith, G. A. (1964). Fat absorption studies in various forms of steatorrhea. American fournal of Clinical Nutrition, 15, 293.

Playoust, M. R., and Isselbacher, K. J. (1964). Studies on the intestinal absorption and intramucosal lipolysis of a medium chain triglyceride. Fournal of Clinical Investigation, 43, 878.

Poley, J. R., Lesch, P., Hitzig, W. H., and Prader, A. (1967). Chylöser Ascites Untersuchungen über den Eiweissstoffwechsel 
und über den Einfluss des Nahrungsfetts auf die Ascitesproduktion. Helvetica Paediatrica Acta, 22, 81 .

Samson, F. E., Jr., Dahl, N., and Dahl, D. R. (1956). A study on the narcotic action of the short chain fatty acids. Fournal of Clinical Investigation, 35, 1291.

Scheig, R. (1968a). Hepatic metabolism of medium chain fatty acids. In Medium Chain Triglycerides p. 39 . Ed. by J. R. Senior. University of Pennsylvania Press, Philadelphia.

- (1968b). Absorption of dietary fat: uses of medium-chain triglycerides in malabsorption. American fournal of Clinical Nutrition, 21, 300.

- (1969). What is dietary fat? American fournal of Clinical Nutrition, 22, 651.

Schizas, A. A., Cremen, J. A., Larson, E., and O'Brien, R. (1967). Medium-chain triglycerides: use in food preparation. fournal of the American Dietetic Association, 51, 228.

Senior, J. R. (1969). The place of medium chain triglycerides. American fournal of the Medical Sciences, 257, 75.

Sun, D. C. H., Albacete, R. A., and Chen, J. K. (1967). Malabsorption studies in cirrhosis of the liver. Archives of Internal Medicine, 119, 567.
Tabaqchali, S., and Booth, C. C. (1967). Relationship of the intestinal bacterial flora to absorption. British Medical Bulletin, 23, 285.

Tamir, I., Gould, S., Fosbrooke, A. S., and Lloyd, J. K. (1969). Serum and adipose tissue lipids in children receiving mediumchain triglyceride diets. Archives of Disease in Childhood, 44, 180.

- , Grant, D. B., Fosbrooke, A. S., Segall, M. M., and Lloyd, J. K. (1968a). Effects of a single oral load of medium-chain triglyceride on serum lipid and insulin levels in man. fournal of Lipid Research, 9, 661.

_, Hunter, J. O., Fosbrooke, A. S., and Lloyd, J. K. (1968b). Serum and chyle lipids during medium-chain triglyceride feeding in a child with chylothorax. Archives of Disease in Childhood, 43, 302.

Townley, R. R. W., and Anderson, C. M. (1967). Coeliac disease a review. Ergebnisse der inneren Medizin und Kinderheilkunde, 26, 1.

Warwick, W. J., Holman, R. T., Quie, P. G., and Good, R. A. (1959). Chylous ascites and lymphedema. American fournal of Diseases of Children, 98, 317. 